\title{
In vitro clonal propagation of Coscinium fenestratum (Gertn.) Colebr. (Weniwel) through nodal explants
}

\author{
P.S. Warakagoda ${ }^{1 *}$, S. Subasinghe ${ }^{1}$ and M.T.K. Gunasekare ${ }^{2}$ \\ ${ }^{\prime}$ Department of Crop Science, Faculty of Agriculture, University of Ruhuna, Mapalana, Kamburupitiya. \\ ${ }^{2}$ Coordinating Secretariat for Science, Technology and Innovation, $3^{\text {rd }}$ Floor, Standard Chartered Building, Janadhipathi Mawatha, Colombo 01.
}

Revised: 25 July 2016; Accepted: 20 October 2016

\begin{abstract}
An in vitro clonal propagation protocol for Coscinium fenestratum was developed using shoot explants detached from $1-2$ year old vines maintained under plant house conditions, by successfully surface sterilising with $0.2 \%$ solution of mercuric chloride for 30 minutes followed by two successive washings with sterilised distilled water. McCowns woody plant medium (WPM) incorporated with $1.0 \mathrm{mgL}^{-1}$ polyvinylpyrrolidone to minimise browning, was the best medium for establishment of nodal cuttings.
\end{abstract}

Mature double nodal cuttings resulted in the highest shoot proliferation rate (3.90 shoots/explant) when cultured on WPM medium supplemented with $2.0 \mathrm{mgL}^{-1}$ 6-benzylaminopurine, $1.0 \mathrm{mgL}^{-1}$ thidiazuron and $0.4 \mathrm{mgL}^{-1} 2,4$-dichlorophenoxyacetic acid. Shoots were separated and transferred to WPM medium devoid of plant growth regulators for regeneration into plantlets. The plantlets were successfully acclimatised on coir dust: sand (1:1) potting media with over $60 \%$ survival rate. The results proved that the protocol developed is effective for clonal propagation of $C$. fenestratum.

Keywords: In vitro clonal propagation, proliferation, shoot explants, surface sterilisation, WPM medium.

\section{INTRODUCTION}

Coscinium fenestratum (Gaertn.) Colebr. (Menispermaceae) is a dioecious large woody climber, which is extensively used in Sri Lanka as a common remedy to heal many diseases. The stems and roots are extensively used in ayurvedic preparations for treating digestive disorders, chronic fevers, wounds, snake bites, ulcers, jaundice, burns, skin diseases, abdominal disorders, diabetes and general debility in South India and Sri Lanka. The root bark is used for dressing wounds, ulcers and in cutaneous leishmaniasis (Tushar et al., 2008).
C. fenestratum is indigenous to the Indo-Malayan region and is found in India, Malaysia, Vietnam, Myanmar, Singapore, Thailand and Sri Lanka (Tushar et al., 2008). It is naturally abundant in forest fringes and disturbed forests in the low country Wet Zone of Sri Lanka (Jayaweera, 2006).

According to the 1997 IUCN red list of threatened species, C. fenestratum is recorded as critically endangered in many countries including Sri Lanka (Walter \& Gillett, 1998). As reported by Agusta (2003), and An and Ziegler (2001), C. fenestratum has already been listed as an endangered species in India and Sri Lanka. To reach maturity and fruiting stage, the plants take at least 15 years due to its slow growth habit (Tushar et al., 2008). Furthermore, destructive harvesting even before maturity, zero cultivation, habitat specificity, and destruction of natural habitats result in a diminishing population of $C$. fenestratum.

Propagation of $C$. fenestratum is commonly done by seeds. There are several limitations for seed propagation; seeds can be seen only once a year and these have hard seed coats and the viability of seeds are lost quickly under low moisture conditions (Senerath, 1991; Kathriarachchi et al., 2004). Within a population, only around $30 \%$ of plants generate flowers during a flowering season (Van \& Tap, 2008). Under natural conditions, seed germination was found to be $23-26 \%$, and $12 \%$ of the fresh fruits were found to contain non-viable seeds (Senerath, 1991). Conventional vegetative propagation through stem cuttings and air layering reported were unsuccessful (Gunatillake et al., 2002).

\footnotetext{
* Corresponding author (priyanwada_sajee@yahoo.com)
} 
Preliminary studies on in vitro multiplication of C. fenestratum carried out by Nair and Seeni (2003) was reported by Tushar et al. (2008). In a previous study on in vitro propagation of $C$. fenestratum epicotyls excised from in vitro germinated seedlings were used as explants (Senarath, 2010). However, it is not possible to germinate seeds in vitro as described without breaking the dormancy (Warakagoda \& Subasinghe, 2014; 2015) and the method is not encountered as a clonal propagation protocol due to the heterogeneous nature of epicotyl explants.

Therefore, identification of feasible propagation techniques is crucial to fulfill the unlimited demand in the island for ayurvedic drug, cosmetic and personal care product manufacturing companies as well as for the conservation of this valuable species. The present investigation was aimed at developing a protocol for in vitro clonal propagation of $C$. fenestratum as an alternative method to the conventional propagation methods, so as to ensure conservation and sustainable use of this valuable plant.

\section{METHODOLOGY}

All the experiments were carried out at the Tissue Culture Laboratory, Department of Crop Science, Faculty of Agriculture, University of Ruhuna, Mapalana, Kamburupitiya, Sri Lanka.

\section{Surface sterilisation of shoots}

Shoot tips $(\leq 1.0 \mathrm{~cm})$ and subsequent single $(1.0-2.0 \mathrm{~cm})$ and double nodal cuttings $(\geq 2.0 \mathrm{~cm})$ having dormant axiliary buds were excised from 2-wk old fresh and young axiliary shoots initiated from nodes on the stems of mother plants maintained at the plant house. The explants were immediately dipped in distilled water after excision. Shoot tips and nodal segments, after removing the leaflets, were treated with liquid detergent (Teepol $5 \% \mathrm{v} / \mathrm{v}$ ) for $5 \mathrm{~min}$ and placed under running tap water for $30 \mathrm{~min}$ followed by immersion in a $3 \%(\mathrm{w} / \mathrm{v})$ Topsin solution (fungicide) for $1 \mathrm{~h}$. Then the explants were treated with 3 different Clorox ${ }^{\mathrm{TM}}(5.25 \% \mathrm{NaOCl})$ concentrations $[10,15,20 \%(\mathrm{v} / \mathrm{v})]$ for 3 different exposure times $(10,15,20 \mathrm{~min})$ inside a lamina air flow cabinet. To enhance the activity of the detergent, 2 drops of Tween 20 (polyoxyethelene sorbitanmonolaurate), a surfactant, was mixed with the Clorox ${ }^{\mathrm{TM}}$ solutions. Then they were dipped in $70 \%(\mathrm{v} / \mathrm{v})$ ethanol for $2 \mathrm{~min}$. After exposing to each solution the explants were thoroughly washed twice using sterilised distilled water. Finally, cut ends of the explants were trimmed and inoculated vertically on a basal MS (Murashige \& Skoog, 1962) medium.
Since negative results were obtained, the surface sterilisation procedure was redesigned by using 2 concentrations [0.1\% and $0.2 \%(\mathrm{w} / \mathrm{v})$ ] of mercuric chloride $\left(\mathrm{HgCl}_{2}\right)$ for 2 exposure time durations (15 and $30 \mathrm{~min}$ ) as the disinfectant. To see the effect of ethanol on controlling contaminations, surface sterilised explants with $\mathrm{HgCl}_{2}$ were introduced either to 50 or $70 \%(\mathrm{v} / \mathrm{v})$ solutions of ethanol for $30 \mathrm{~s}$ or $2 \mathrm{~min}$. After exposing to each solution the explants were thoroughly washed using sterilised distilled water twice. Numbers of aseptic cultures were recorded during the culture period up to 4 wks.

\section{In vitro establishment of shoots}

Surface sterilised shoot tips and subsequent single and double nodal cuttings were cultured on MS and McCown's woody plant medium (WPM) (Lloyd \& Mc Cown' 1981) media vertically and horizontally. Activated charcoal (AC) $\left(1.0,5.0\right.$ and $\left.10 \mathrm{gL}^{-1}\right)$ and polyvinylpyrrolidone (PVP) $\left(0.5,1.0\right.$ and $\left.3.0 \mathrm{gL}^{-1}\right)$ as absorbents, and ascorbic acid $\left(0.1,0.25\right.$ and $\left.0.5 \mathrm{gL}^{-1}\right)$ and citric acid $(0.1,0.5$ and $\left.1.0 \mathrm{gL}^{-1}\right)$ as antioxidants were added to culture media separately. Numbers of culture media that turned brown were assessed during the 4-wk culture period.

\section{In vitro shoot proliferation}

For all the experiments, WPM medium was used as the basal medium as it is superior to MS medium during culture establishment. All the media contained $1.0 \mathrm{gL}^{-1}$ PVP as the anti-browning agent.

\section{Effects of plant growth regulator (PGR) combination on multiple shoot induction}

Four weeks after the establishment of aseptic cultures, buds which initiated double nodal explants on basal WPM medium were transferred to WPM media containing different concentrations of either 6-benzylaminopurine (BAP) or kinetin (Kin) (1.0, 3.0 or $\left.5.0 \mathrm{mgL}^{-1}\right)$ combined with either indole-3-acetic acid (IAA), naphthaleneacetic acid (NAA) or 2, 4-dichlorophenoxyacetic acid (2, 4-D) $\left(0.0,0.2\right.$ or $\left.0.4 \mathrm{mgL}^{-1}\right)$. Since negative results were obtained, the experiment was rearranged using the above mentioned concentrations of BAP with Kin $(0.5,1.0,2.0$ or $\left.4.0 \mathrm{mgL}^{-1}\right)$ and IAA, NAA or $2,4-\mathrm{D}\left(0.0\right.$ or $\left.0.4 \mathrm{mgL}^{-1}\right)$. With repeated negative results, the experiment was redesigned using thidiazuron (TDZ) $\left(0.5,1.0,2.0 \mathrm{mgL}^{-1}\right)$ in combination with $\operatorname{BAP}\left(0.0,1.0,2.0,3.0 \mathrm{mgL}^{-1}\right)$ and IAA, NAA or 2, 4-D $\left(0.0,0.2\right.$ or $\left.0.4 \mathrm{mgL}^{-1}\right)$, which resulted in positive results. The number of shoots and leaves per explant were evaluated up to $12 \mathrm{wks}$. 


\section{Effects of explant type on multiple shoot induction}

A separate experiment was conducted to evaluate the influence of explant type on in vitro shoot proliferation ability. Explants were collected from 2-wk old fresh and young axiliary shoots initiated from nodes on the pruned stems of mother plants and collected into separate beakers labelled as shoot tips, immature and mature nodal and double nodal cuttings. Single and double nodal cuttings were divided into 2 maturity stages as immature and mature. Easy to excise cuttings using a scalpel were considered as immature and hard to excise were considered as mature cuttings. Excised cuttings adjoining the shoot apexes were usually immature and those which were excised further from the shoot tips were mature in nature.

After surface sterilisation, the shoots were inoculated on WPM media containing $1.0 \mathrm{gL}^{-1} \mathrm{PVP}$ for 4 wks while maintaining the identity of the explant type. Then they were transferred to WPM media containing $2.0 \mathrm{mgL}^{-1} \mathrm{BAP}, 1.0 \mathrm{mg} \mathrm{L}^{-1} \mathrm{TDZ}$ and $0.4 \mathrm{mg} \mathrm{L}^{-1}$ 2, 4-D for multiplication. Number of shoots and leaves per explant were assessed up to $12 \mathrm{wks}$.

\section{Effects of BAP spray on mother plants on multiple shoot induction}

Mother plants ( $1-2$ year old) were grouped into 5 and treated separately with one of the concentrations of $(25$, $50,100,200$ and $\left.500 \mathrm{mgL}^{-1}\right) \mathrm{BAP}$ at $2 \mathrm{wk}$ intervals as a foliar spray to evaluate its effects on axillary shoot induction from cultured explants. Another group of 5 mother plants were treated as mentioned above weekly. Mature double nodal cuttings were collected for in vitro culturing after 1, 3, 5 and 7 days after BAP spray. After surface sterilisation they were introduced to WPM media containing $1.0 \mathrm{gL}^{-1} \mathrm{PVP}$ for 4 wks while maintaining the above labelling system. Then they were introduced to WPM media containing $2.0 \mathrm{mgL}^{-1} \mathrm{BAP}, 1.0 \mathrm{mgL}^{-1} \mathrm{TDZ}$ and $0.4 \mathrm{mgL}^{-1} 2$, 4-D for multiplication. Time taken for initiation of the first shoot bud and the number of shoots formed per explant were measured up to 12 wks.

\section{Effects of pulse treatment on multiple shoot induction}

To evaluate the effect of pulse treatment on adventitious shoot induction, higher concentrations of BAP alone and in combination with Kin in similar concentrations (25, 50, 100, 150 and $200 \mathrm{mgL}^{-1}$ ) were tested. After 1, 3, 6, and $24 \mathrm{~h}$ the treated shoots were transferred to solid basal WPM medium.
A separate experiment was conducted using the best plant growth regulator combination $\left(2.0 \mathrm{mgL}^{-1} \mathrm{BAP}\right.$, $1.0 \mathrm{mgL}^{-1} \mathrm{TDZ}$ and $0.4 \mathrm{mgL}^{-1}$ 2, 4-D), which gave the highest shoot proliferation rate as the pulse treatment. Shoots were slightly shaken at $50 \mathrm{rpm}$ for $6 \mathrm{~h}, 1,3,7$, 14 and 21 ds followed by transferring to solid basal WPM media or WPM media containing the same PGR combination.

Mature double nodal cuttings were used as the explants. To minimise any adverse effect of phenolic exudates secreted into the solutions used for pulse treatments, an anti-browning agent $\left(1.0 \mathrm{gL}^{-1} \mathrm{PVP}\right)$ was introduced. Time taken for the initiation of first shoot bud and the number of shoots formed per explant were measured up to 12 wks of observation period.

\section{In vitro elongation of plantlets}

During the proliferation stage, inter nodal length of the shoots produced from the nodes of the double nodal cuttings were very low forming shoot clumps. Since it was very difficult to separate the shoots due to their low height, sub culturing aiming further multiplication was not practiced. Instead, to enhance inter nodal length, 4 different concentrations of $\mathrm{GA}_{3}(0.5,1.0,1.5$ and $2.0 \mathrm{mgL}^{-1}$ ) were incorporated into the proliferation medium. Another set of multiplied shoots without separation were transferred to WPM media containing the above concentrations of $\mathrm{GA}_{3}$. As the control, WPM basal medium was used.

\section{Acclimatisation procedure}

\section{Acclimatisation stage 01}

After 4 wks from root formation, culture bottles containing in vitro rooted plants were taken out from the culture room and placed under normal laboratory conditions for a week. The culture bottles were then placed in a shade house for $3 \mathrm{ds}$.

\section{Acclimatisation stage 02}

Lids of the culture vessels were opened and a mixture of $0.6 \mathrm{mgL}^{-1}$ Captan $^{\mathrm{TM}}$ and $0.7 \mathrm{mgL}^{-1}$ Thiram $^{\mathrm{TM}}$ fungicides was sprayed on plants inside the containers. They were placed inside a propagator and kept inside the shade house for another 3 ds. To maintain high humidity, regular spraying of water was needed at least twice a day. 


\section{Acclimatisation stage 03}

Plantlets were taken out from the bottles and the roots were thoroughly washed using lukewarm water at least thrice. Then the plantlets were dipped in a mild fungicide $\left(0.6 \mathrm{mgL}^{-1} \mathrm{Captan}^{\mathrm{TM}}\right)$ solution for $15 \mathrm{~min}$ and transferred to poly bags containing sand and coir dust (1:1 ratio). Potting medium was mixed with 'Osmocot', a slow release high nitrogen fertiliser, a week before usage. After 8 wks, the plants were transferred to poly bags containing cow dung: top soil: sand (1:1:1 ratio) and kept under shade house conditions for another 4 wks before introducing to the field. Survival rates were measured throughout the experimental period of 14 wks.

\section{Experimental design and statistical analysis}

All the experiments were designed according to the factorial randomised complete block design (RCBD) with 10 replicates. Each experiment was repeated 3 times. Non contamination percentages, browning percentages, number of new shoot buds and leaves appeared and survival rates were recorded weekly. Data were analysed using SAS statistical software.

\section{RESULTS AND DISCUSSION}

\section{Surface sterilisation of shoots}

All the explant types were severely contaminated with bacterial and fungal contaminants within a week even after treating with $20 \%$ Clorox $^{\mathrm{TM}}$ for 20 minutes. Bacterial oozes secreted to culture medium and fungal mycelia were prominent on the surface of the medium after the second week from culture establishment.

However, for surface sterilisation of both shoot tips and nodal cuttings, interactions of the $\mathrm{HgCl}_{2}$ concentration and exposure time were significantly effective for controlling contaminations at $\mathrm{p} \leq 0.05$ probability level. The treatment with $0.2 \% \mathrm{HgCl}_{2}$ for 30 minutes was found to be the best for shoot tips and nodal cuttings with $99 \%$ and $88 \%$ mean non contamination rates, respectively (Table 1). It was further observed that double nodal cuttings were contaminated more frequently compared to single nodal cuttings.

Dipping the explants either in $50 \%$ or $70 \%$ ethanol for 30 seconds or two minutes after treating the explants with $0.2 \% \mathrm{HgCl}_{2}$ for 30 minutes was not significantly effective at $p \leq 0.05$ level on mean non-contamination percentages of shoot tips and nodal cuttings (Figure 1).
Table 1: Mean non-contamination rates resulted with different concentrations of $\mathrm{HgCl}_{2}$ and exposure times

\begin{tabular}{lccc}
\hline $\begin{array}{l}\text { Mercuric } \\
\text { chloride } \\
\text { concentration }\end{array}$ & $\begin{array}{c}\text { Exposure } \\
\text { time }\end{array}$ & \multicolumn{2}{c}{ Mean non contamination rate $(\%) \pm \mathrm{SE}$} \\
\hline & & Shoot tips & Nodal cuttings \\
\hline $0.1 \%$ & 15 minutes & $20.50^{\mathrm{d}} \pm 3.87$ & $11.00^{\mathrm{d}} \pm 4.39$ \\
$0.1 \%$ & 30 minutes & $59.00^{\mathrm{c}} \pm 4.39$ & $38.66^{\mathrm{c}} \pm 5.03$ \\
$0.2 \%$ & 15 minutes & $79.00^{\mathrm{b}} \pm 4.39$ & $79.00^{\mathrm{b}} \pm 4.39$ \\
$0.2 \%$ & 30 minutes & $99.00^{\mathrm{a}} \pm 4.39$ & $88.00^{\mathrm{a}} \pm 7.08$ \\
& & $\mathrm{CV}=5.77$, & $\mathrm{CV}=10.92$, \\
& & $\mathrm{LSD}=2.32$ & $\mathrm{LSD}=2.81$ \\
\hline
\end{tabular}

Means represented by the same letter in each column are not significantly different at $\mathrm{p} \leq 0.05$ probability level $(\mathrm{SE}=$ standard error, $\mathrm{CV}=$ coefficient of variation, $\mathrm{LSD}=$ least significant difference)

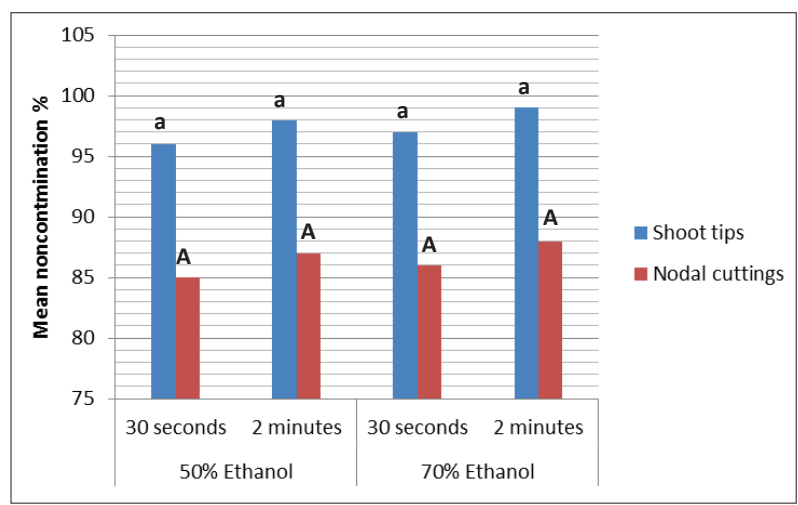

Figure 1: Effect of ethanol on mean non-contamination percentages of shoot tips and nodal cuttings

Means represented by the same letter-case on the bars are not significantly different at $\mathrm{p} \leq 0.05$ probability level

$\mathrm{HgCl}_{2}$ has been used as a surface sterilant in plant tissue culture since decades especially when microbial contaminations are very difficult to control. During the study to avoid bacterial and fungal contaminations, the only effective treatment procedure was found to be dipping the explants in $0.2 \% \mathrm{HgCl}_{2}$ solution for 30 minutes.

Browning of explant tissues due to any surface sterilant was not detected since the shoots and immature leaves of this species are naturally brown in colour.

It has been reported by Rodriguez et al. (1989) that during surface sterilisation of adult material (shoot segments) of Juglans spp., the last step was to submerge them in $\mathrm{HgCl}_{2}(0.05 \% \mathrm{w} / \mathrm{v})$ for 5 minutes, and in certain 
cases submerging in $\mathrm{HgCl}_{2}\left(1-2 \mathrm{mgL}^{-1}\right)$ for 10 minutes was the best. In another experiment, the suitability of Clorox ${ }^{\mathrm{TM}}$ and $\mathrm{HgCl}_{2}$ as sterilising agents was tested on seeds collected from wild mature trees of Aquilaria malaccensis and leaf and nodal explants excised from shade house grown $4-5$ year old plants. The best treatment identified for seeds, leaves and nodal explants was dipping in $0.2 \% \mathrm{HgCl}_{2}$ for 12 minutes, $0.1 \% \mathrm{HgCl}_{2}$ for 15 and 30 seconds, respectively (Daud et al., 2012).

\section{In vitro establishment of shoots}

Browning of the culture medium was not significantly affected at $\mathrm{p} \leq 0.05$ level by the three factor interactions of type of the explant, culture medium and anti-browning agents. However, anti-browning agents present in the culture media significantly $(p \leq 0.05)$ reduced browning as a single factor. Phenolic exudates released into the culture media by shoot tips and nodal cuttings were significantly minimised up to $80 \%, 79 \%$ and $78 \%$ by $3.0 \mathrm{gL}^{-1}$ and $1.0 \mathrm{gL}^{-1}$ PVP followed by $10.0 \mathrm{gL}^{-1} \mathrm{AC}$, respectively in both MS and WPM media at $\mathrm{p} \leq 0.05$ probability level (Figure 2).

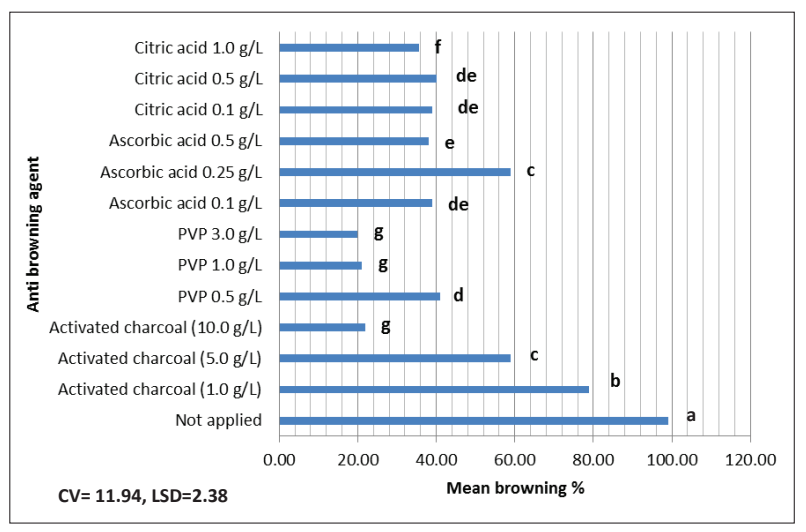

Figure 2: Effect of anti-browning agents on mean browning rates of culture media

Means represented by the same letter are not significantly different at $\mathrm{p} \leq 0.05$ probability level

Although not significant at $\mathrm{p} \leq 0.05$ level, the WPM medium $(45.46 \%)$ is less prone to browning compared to MS medium (46.33\%) (data not shown). Further, axillary buds were initiated only from the nodes of the double nodal cuttings cultured on WPM medium (Figure 3a).

Explants cultured horizontally on both media were easily contaminated by bacterial and fungal infections. When horizontally cultured, the surface area of explants touching the nutrient medium is much higher than when placed vertically, which may promote the growth of many suppressed contaminants.

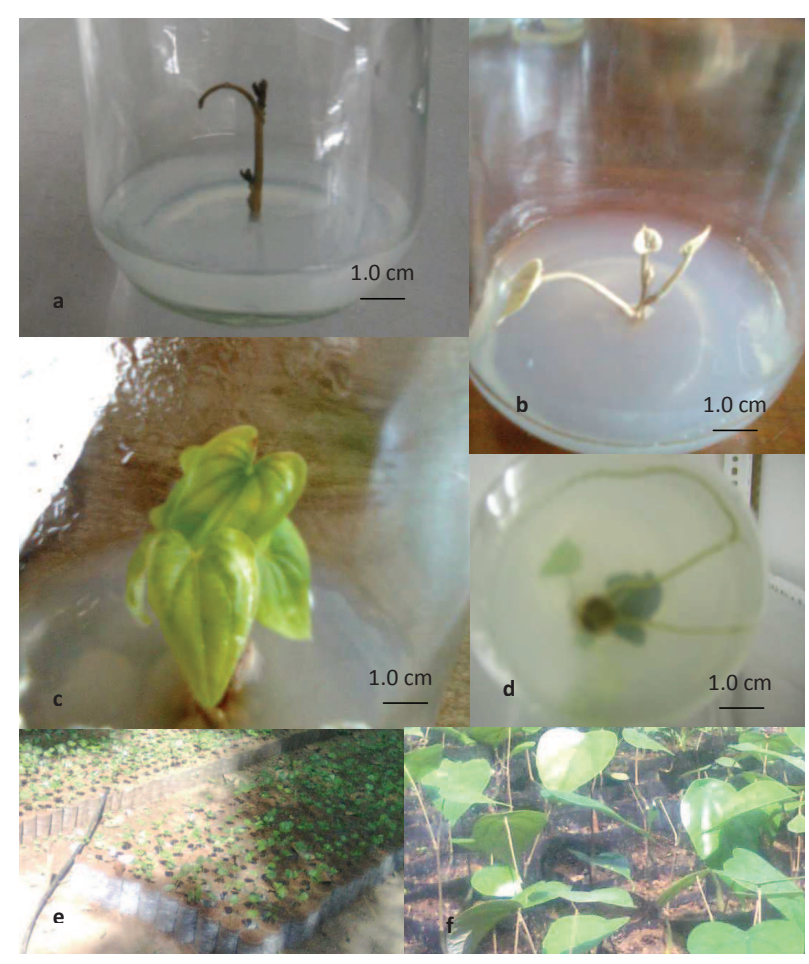

Figure 3: (a) Buds initiated from nodes of mature double nodal explant on WPM medium; (b) single shoot transferred into same new medium for further multiplication after excision from a shoot clump; (c) brown colour leaves of the shoot eventually turned into green colour after 8 weeks; (d) micro cutting with elongated roots six weeks after introducing to WPM medium; (e) plantlets at acclimatisation stage 3 (after introducing to sand: coir dust medium); (f) plants in poly bags containing cow dung: top soil: sand $(1: 1: 1)$

\section{In vitro shoot proliferation}

\section{Effect of plant growth regulator combinations on multiple shoot induction}

As it has been recorded that some auxins in minor concentrations promote shoot proliferation when applied with cytokinins (Machakova et al., 2008), three concentrations of IAA, NAA and 2, 4-D were introduced to BAP or/and Kin containing media. However, up to six months of observation period none of the shoots produced new shoots, branches or leaves.

Therefore, the experiment was redesigned using TDZ, which gave promising results only in the presence 
of $0.4 \mathrm{mgL}^{-1} 2,4$-D. Two factor interactions of BAP and TDZ significantly $(\mathrm{p} \leq 0.05)$ affected the mean number of shoots produced by double nodal cuttings within the 8 week observation period. During the multiplication phase, the highest number of shoots (3.90 shoots/ explant) was observed in $0.4 \mathrm{mgL}^{-1} 2$, 4-D containing WPM medium when $2.0 \mathrm{mgL}^{-1} \mathrm{BAP}$ and $1.0 \mathrm{mgL}^{-1} \mathrm{TDZ}$ were fortified in addition (Table 2).

Table 2: Effect of concentration and combination of cytokinins on mean number of shoots and leaves produced by mature double nodal cuttings cultured on WPM medium containing $0.4 \mathrm{mgL}^{-1}$ 2, 4-D (after 8 weeks)

\begin{tabular}{|c|c|c|c|}
\hline Cytok & $\left.\mathrm{ngL}^{-1}\right)$ & Mean number of & Mean number of \\
\hline BAP & TDZ & & \\
\hline 0.00 & 0.20 & $0.80^{\mathrm{g}} \pm 0.41$ & $0.75^{\mathrm{e}} \pm 0.44$ \\
\hline & 0.50 & $0.85^{\mathrm{g}} \pm 0.41$ & $0.80^{\mathrm{e}} \pm 0.41$ \\
\hline & 1.00 & $1.25^{\mathrm{f}} \pm 0.44$ & $2.20^{\mathrm{d}} \pm 0.41$ \\
\hline & 2.00 & $0.84^{\mathrm{g}} \pm 0.37$ & $0.84^{\mathrm{e}} \pm 0.37$ \\
\hline 1.00 & 0.20 & $0.85^{\mathrm{g}} \pm 0.36$ & $0.90^{\mathrm{e}} \pm 0.30$ \\
\hline & 0.50 & $0.90^{\mathrm{g}} \pm 0.30$ & $0.95^{\mathrm{e}} \pm 0.22$ \\
\hline & 1.00 & $1.80^{\mathrm{c}} \pm 0.41$ & $2.80^{\mathrm{c}} \pm 0.41$ \\
\hline & 2.00 & $1.15^{\mathrm{f}} \pm 0.37$ & $1.05^{\mathrm{e}} \pm 0.40$ \\
\hline 2.00 & 0.20 & $1.25^{\mathrm{f}} \pm 0.55$ & $1.00^{\mathrm{e}} \pm 0.32$ \\
\hline & 0.50 & $1.55^{\mathrm{e}} \pm 0.51$ & $1.50^{\mathrm{e}} \pm 0.51$ \\
\hline & 1.00 & $3.90^{\mathrm{a}} \pm 0.30$ & $6.10^{\mathrm{a}} \pm 0.30$ \\
\hline & 2.00 & $1.63^{\mathrm{d}} \pm 0.49$ & $1.42^{\mathrm{e}} \pm 0.50$ \\
\hline 3.00 & 0.20 & $1.30^{\mathrm{f}} \pm 0.73$ & $1.20^{\mathrm{e}} \pm 0.41$ \\
\hline & 0.50 & $1.20^{\mathrm{f}} \pm 0.61$ & $1.20^{\mathrm{e}} \pm 0.41$ \\
\hline & 1.00 & $2.95^{b} \pm 0.22$ & $3.75^{b} \pm 0.44$ \\
\hline & 2.00 & $1.05^{\mathrm{g}} \pm 0.22$ & $1.10^{\mathrm{e}} \pm 0.30$ \\
\hline & & $\mathrm{CV}=9.89$ & $\mathrm{CV}=11.34$ \\
\hline & & $\mathrm{LSD}=0.26$ & $\mathrm{LSD}=0.22$ \\
\hline
\end{tabular}

Means represented by the same letter in each column are not significantly different at $\mathrm{p} \leq 0.05$ probability level $(\mathrm{n}=10)$

The tested concentrations of Kin even when combined with TDZ were not effective in multiple shoot production (data not shown). Produced shoots were separated after 8 weeks and transferred to the same media $\left(1^{\text {st }}\right.$ sub culture) for further multiplication. They were not multiplied further, however, brown colour minute leaf primodia turned into light green colour and leaf laminas were enlarged (Figures $3 \mathrm{~b}$ and $3 \mathrm{c}$ ).

The number of leaves produced were significantly $(p \leq 0.05)$ affected by the concentrations of BAP and TDZ incorporated into $0.4 \mathrm{mgL}^{-1}$ 2, 4-D fortified WPM culture media. The highest number of leaves ( 6.10 leaves per shoot) was recorded in the presence of $2.0 \mathrm{mgL}^{-1} \mathrm{BAP}$ and $1.0 \mathrm{mgL}^{-1} \mathrm{TDZ}$ (Table 2). Tested concentrations of IAA and NAA did not form leaves in the presence of cytokinins. Other than $0.4 \mathrm{mgL}^{-1}$, rest of the tested concentrations of 2, 4-D were not successful in forming leaves (data not shown).

TDZ is among the most active cytokinin-like substances for woody plant tissue culture. It facilitates efficient micropropagation of many recalcitrant woody species (Parthasarathy, 2007). Although low concentrations $\left(<0.25 \mathrm{mgL}^{-1}\right)$ of TDZ can induce greater axillary bud proliferation than many other cytokinins it may inhibit shoot elongation (Sathyanarayana \& Varghese, 2007). In some cases it is necessary to transfer the shoots to an elongation medium containing a lower level of TDZ and/or a less active cytokinin (Huetteman \& Preece, 1993). However, it was mentioned that most commonly used cytokinins in plant tissue culture including Zeatin, Kin, BA, TDZ and 2-iP can be applied in higher concentrations $1-10 \mu \mathrm{M}\left(0.2-2.0 \mathrm{mgL}^{-1}\right)$ for adventitious shoot formation, while suppressing the apical dominance regulated by auxins (Staden et al., 2008).

\section{Effect of explant type on multiple shoot induction}

It was observed that only mature double nodal cuttings produced multiple shoots, while shoot tips and other cutting types did not produce any shoots. Similar results were shown by some other plants (e.g. Eucalyptus), where a bud bearing node is a more reliable initial explant for shoot cultures than a dissected shoot apex (Gahan \& George, 2008). It was also recorded that twonode explants for all cultivars of Buddleia produced higher multiplication rates compared to those of single nodes and apical tips (Phelan et al., 2005).

It is important to identify the correct maturity stage of the shoots prior to excision of explants from mother plants to achieve highest shoot proliferation. However, the selection of an explant of the optimum 'age' for micropropagation can sometimes be complex. In Rosa hybrida, single node explants ( $1.0 \mathrm{~cm}$ of stem plus a bud) taken from new shoots, which grew after the bushes were pruned, where the new shoots reached $10 \mathrm{~cm}$ height and having six axillary buds were the best. All the lateral buds were then capable of growing in vitro. Much less reliable explants were obtained from shoots, which had extended until they bore terminal flower buds. Explants, which grew well and produced vigorous shoots could then only be obtained from middle order buds. By the time the shoots were over $60 \mathrm{~cm}$ in length, growth of cultured buds was erratic. Similarly when single node 
explants from tomato plants at the seventh leaf stage were cultured, buds from nodes $1-3$ grew slowly, those from nodes 4 and 5 grew most rapidly and those from node 6 grew slightly less quickly (Gahan \& George, 2008).

Therefore, based on the results it can be concluded that after two weeks from axillary shoot initiation on pruned mother plants, the distal nodes must be at the correct maturity stage with the capacity to produce in vitro growing buds. After this stage inter nodal length of the shoots increased and brown colour immature leaves eventually turned into light green colour.

\section{Effect of BAP spray on mother plants on multiple shoot induction}

In commercial in vitro propagation a major disadvantage identified was the dependence on a special development phase of the mother plant especially when organs are used for explantation (Sathyanarayana et al., 2007). To break dormancy of the explants cytokinins can be applied to the mother plants. A $100 \mathrm{mgL}^{-1}$ solution of BAP or more can be sprayed or $500 \mathrm{mg} \mathrm{L}^{-1}$ can be injected to the mother plants (Neumann et al., 2009). However, during this study either shoot bud initiation or the number of shoots produced per explant was not significantly affected at $\mathrm{p} \leq 0.05$ level by the excised date of explants from mother plants, after spraying of any tested concentrations of BAP weekly or at two week intervals to the mother plants (data not shown). As the sprayings were not successful, injection of BAP into the mother plants was not practiced.

\section{Effect of pulse treatment on multiple shoot induction}

It was recorded that exposure of explants to higher concentrations of cytokinins for a short period of time (pulse treatment) is resorted to before transferring into either basal culture media or media consisting the same cytokinin in lower concentrations to enhance shoot multiplication ability (Staden et al., 2008). In certain occasions it was recorded that the combination of cytokinin and auxin for a period of up to $7-14$ days followed by transferring to PGR free media is more effective (Beyl, 2011). However, during the present study none of the treatment combinations used as pulse treatment was effective (data not shown).

\section{In vitro elongation of plantlets}

During the multiplication stage inter nodal length of the shoots produced from the nodes of the double nodal cuttings were very low forming shoot clumps with a few prominent shoot apices. Therefore, it was difficult to separate the shoots to be introduced into proliferation media for further multiplication. Even when separated from shoot clumps and introduced to the proliferation medium they never multiplied may be due to their minute size. It was reported that shoots should be treated with $\mathrm{GA}_{3}$ to increase the length of the shoots during multiplication, or prior to rooting. Further, $\mathrm{GA}_{3}$ was beneficial especially when higher levels of cytokinins has resulted in many short shoots (Moshkov et al., 2008).

Therefore, in this study to enhance inter nodal length, three different concentrations of $\mathrm{GA}_{3}$ were applied into the proliferation medium. However, as there was no effect of the above media on shoot length, multiplied shoots were transferred to WPM media containing three different concentrations of $\mathrm{GA}_{3}$. As the control, WPM basal medium was used. Within four weeks, one prominent shoot elongated (up to $2.5 \mathrm{~cm}$ ) from the shoot clumps on basal WPM media and roots were formed from the lower node of the initial explant. Therefore, it was decided to separate multiplied shoots from the initial explant as much as possible (maximum up to three) before introducing to basal WPM media. Shoots were elongated up to a mean height of $3.0 \mathrm{~cm}$ and mean three roots per plantlet ( $4.3 \mathrm{~cm}$ mean root length) were formed within four weeks from culture initiation (Figure 3d). It is a must to excise shoots immediately after a node, and at least leaving two nodes per shoot to facilitate shoot elongation and rooting after introducing to basal WPM medium.

Elongated shoots on basal WPM media did not multiply when transferred to the proliferation medium after removing the roots, emphasising the necessity of proper maturity level to form new shoots since mature double nodal cuttings only succeeded as an initial explant. On the other hand this may be due to the removal of habituation effect of cytokinins while on the basal WPM medium. Therefore, with the present findings it was not possible to maintain several multiplication cycles when micropropagating C. fenestratum.

It was reported that among the three concentrations of $\mathrm{GA}_{3}\left(0.0,0.5\right.$ and $\left.2.0 \mathrm{mgL}^{-1}\right), 0.5 \mathrm{mgL}^{-1}$ had no effect on elongating in vitro cultured shoots of Hevea, while $2.0 \mathrm{mgL}^{-1}$ was inhibiting shoot growth. A level of $\mathrm{GA}_{3}$ between these two concentrations may facilitate shoot elongation (Gunatilleke \& Samaranayake, 1988). Further, the support of $\mathrm{GA}_{3}$ up to $0.1 \mathrm{mgL}^{-1}$ on in vitro shoot elongation was identified, where the highest shoot length $(5.6 \mathrm{~cm} / \mathrm{shoot})$ was observed with $0.1 \mathrm{mgL}^{-1}$ within 15 days of culture (Arumugam et al., 2003). Increased concentrations of $\mathrm{GA}_{3}$ suppressed shoot elongation. Similarly during the current study, concentrations 
lower than $0.5 \mathrm{mgL}^{-1}$ (the lowest concentration of $\mathrm{GA}_{3}$ tested during the study) enhanced shoot elongation of $C$. fenestratum. However, since the shoots reached $3.0 \mathrm{~cm}$ height within four weeks without $\mathrm{GA}_{3}$ further attempts were not taken to identify such a concentration.

\section{Acclimatisation procedure}

Plants, after 14 weeks of three stage-acclimatisation procedure during which micro plantlets were gradually adapted to normal environmental conditions with over $60 \%$ survival rate, are transferrable to normal field conditions (Figures $3 e$ and $3 f$ ).

In vitro grown species require a properly designed acclimatisation process in order to ensure a sufficient number of plants to be survived after transferring to soil, since the plant house and field has comparatively lower relative humidity, higher light conditions and septic environment that are stressful to micropropagated plants (Hazarika, 2003). Hence plantlets should be slowly acclimatised to ex vitro conditions with high light intensity and low humidity conditions (Chandra et al., 2010). Under such situation delaying the removal of plantlets from highly humid conditions inside the culture bottles until reaching the mid stage of the acclimatisation process was useful to slowly adapt the plants to low humidity conditions. Further, the plantlets were kept in a propagator and then in a shade house up to 14 weeks with gradual increments of light intensity prior to exposing to field conditions.

\section{CONCLUSION}

Shoot tips and nodal cuttings of $C$. fenestratum can be successfully surface sterilised by dipping the explants for 30 minutes in $0.2 \%$ solution of $\mathrm{HgCl}_{2}$ followed by two successive washings with sterilised distilled water.

McCowns woody plant medium is the best establishment medium for shoot tips and nodal cuttings. Incorporation of $1.0 \mathrm{mgL}^{-1} \mathrm{PVP}$ into culture media is needed to minimise the browning effect.

Mature double nodal cuttings resulted in the highest shoot proliferation rate (3.90 shoots/ explant) when cultured on WPM medium supplemented with $2.0 \mathrm{mgL}^{-1} \mathrm{BAP}, 1.0 \mathrm{mgL}^{-1} \mathrm{TDZ}$ and $0.4 \mathrm{mgL}^{-1} 2$, 4- D. Shoots separated and transferred to basal WPM medium for regeneration into plantlets can be successfully acclimatised on coir dust: sand (1:1) potting media with over $60 \%$ survival rate.

\section{REFERENCES}

1. Agusta A. (2003). Coscinium fenestratum (Gaertner) colebr. Plant Resources in South East Asia No 12: Medicinal and Poisonous Plants 3 (eds. R.M.H.J. Lemens \& N. Bunyapraphatsara), pp. 139 - 140. Backhuys Publishers, Leiden, The Netherlands.

2. An T.T. \& Ziegler S. (2001). Utilization of medicinal plants in Bach Ma National Park, Vietnam. Medicinal Plant Conservation 7: $3-4$.

3. Arumugam S., Rao A.S. \& Rao M.V. (2003). In vitro propagation of Aegle marmelos (L.) Corr. a medicinal tree. Micropropagation of Woody Tree and Fruits (eds. S.M. Jain \& K. Ishii), p. 304. Kluwer Academic Publishers, Dordrecht, The Netherlands.

4. Beyl C.A. (2011). PGRs and their use in micropropagation. Plant Tissue Culture, Development and Biotechnology (eds. R.N. Trigiano \& D.J. Gray), pp. 33 - 56. CRC Press/ Taylor and Francis Group, USA.

5. Chandra S., Bandopadhyay R., Kumar V. \& Chandra R. (2010). Acclimatization of tissue cultured plants: from laboratory to land. Biotechnology Letters 32: 1199 - 1205. DOI: https://doi.org/10.1007/s10529-010-0290-0

6. Daud N.H., Jayaraman S. \& Mohamed R. (2012). An improved surface sterilization technique for introducing leaf, nodal and seed explants of Aquilaria malaccensis from field sources into tissue culture. Asia Pacific Journal of Molecular Biology and Biotechnology 20(2): 55 - 58.

7. Gahan P.B. \& George E.F. (2008). Adventitious regeneration. Plant Propagation by Tissue Culture, $3^{\text {rd }}$ edition (eds. E.F. George, M.A. Hall \& G.D. Klerk), pp. 377 - 383. Springer Science + Business Media, Inc., The Netherlands.

8. Gunatillake I.A.U., Gunatilleke C.V.S., Tennakoon K.U., Dassanayake M.D. \& Wanigasundara W.P.D. (2002). Development of Propagation Techniques for Medicinal Plant Species Solunum album, Coscinium fenestratum, Piper longum and Hemidesmus indicus. Sri Lanka Conservation and sustainable use of Medicinal Plant Project, Ministry of Indigenous Medicine and Disaster Relief Research Report MP/RP/04. Postgraduate Institute of Science, University of Peradeniya, Peradeniya.

9. Gunatilleke I.D. \& Samaranayake C. (1988). Shoot tip culture as a method of micropropagation of Hevea. Journal of the Rubber Research Institute of Sri Lanka 68: 33 - 44.

10. Hazarika B.N. (2003). Acclimatization of tissue-cultured plants. Current Science 85: 1704 - 1712.

11. Huetteman C.A. \& Preece J.E. (1993). Thidiazuron: a potent cytokinin for woody plant tissue culture. Plant Cell, Tissue and Organ Culture 33: $105-119$. DOI: https://doi.org/10.1007/BF01983223

12. Jayaweera D.M.A. (2006). Medicinal Plants (Indigenous and Exotic) used in Ceylon, pp. 70 - 71. National Science Foundation of Sri Lanka, 47/5, Maitland Place, Colombo 07.

13. Kathriarachchi H.S., Tennakoon K.U., Gunatilleke C.V.S., Gunatilleke I.A.U.N \& Ashton P.M.S. (2004). Ecology of two selected liana species of utility value in a lowland 
rain forest of Sri Lanka: implications for management. Conservation and Society 2(2): 273 - 288.

14. Lloyd G. \& McCown B.H. (1981). Commercially feasible micropropagation of mountain laurel, Kalmia latifolia, by use of shoot tip culture. Combined Proceedings of the International Plant Propagators' Society 30: 421 - 427.

15. Machakova I., Zazimalova E. \& George E.F. (2008). Plant growth regulators I: introduction; auxins, their analogues and inhibitors. Plant Propagation by Tissue Culture, $3^{\text {rd }}$ edition (eds. E.F. George, M.A. Hall \& G.D. Klerk), pp. 175 - 204. Springer Science + Business Media, Inc., The Netherlands.

16. Moshkov I.E., Novikova G.V., Hall M.A. \& George E.F. (2008). Plant growth regulators III: gibberellins, ethylene, abscisic acid, their analogues and inhibitors; miscellaneous compounds. Plant Propagation by Tissue Culture, $3^{\text {rd }}$ edition (eds. E.F. George, M.A. Hall \& G.D. Klerk), pp. $227-282$. Springer Science + Business Media, Inc., The Netherlands.

17. Murashige T. \& Skoog F. (1962). A revised medium for rapid growth and bioassay with tobacco tissue cultures. Physiologia Plantarum 15: 473 - 497. DOI: https://doi.org/10.1111/j.1399-3054.1962.tb08052.x

18. Nair L.G. \& Seeni S. (2003). Preliminary studies on in vitro multiplication of Coscinium fenestratum Gaertn. Colebr. Menispermaceae. Journal of Plant Biology 30(1): 85 - 88.

19. Neumann K.-H., Kumar A. \& Imani J. (2009). Plant Cell and Tissue Culture - A Tool in Biotechnology: Basics and Application, p. 81. Springer Verlag, Heidelberg, Germany.

20. Parthasarathy V.A. (2007). High tech propagation of horticultural crops - accent of recalcitrance. Recent Trends in Horticultural Biotechnology (eds. R. Kesharachandran, P.A. Nazeem, D. Girija, P.S. John \& K.V. Peter), pp. $85-$ 91. New India Publishing Agency, New Delhi, India.

21. Phelan S., Hunter A. \& Douglas G. (2005). Bacteria detection and micropropagation of ten Buddleia cultivars. Propagation of Ornamental Plants 5(3): 164 - 169.

22. Rodriguez R., Revilla A., Albuerne M. \& Perez C. (1989). Walnut (Juglans spp.). Biotechnology in Agriculture and Forestry 5: Trees II (ed. Y.P.S. Bajaj), p. 107. Springer-
Verlag, Berlin, Germany.

23. Sathyanarayana B.N. \& Varghese D.B. (2007). Problems in plant tissue culture. Plant Tissue Culture: Practices and New Experimental Protocols, p. 240. I.K. International Publishing House Pvt. Ltd., New Delhi, India.

24. Senarath W.T.P.S.K. (2010). In vitro propagation of Coscinium fenestratum (Gaertn.) Colebr. (Menispermaceae) - an endangered medicinal plant. Journal of the National Science Foundation of Sri Lanka 38(4): 219 - 223. DOI: https://doi.org/10.4038/jnsfsr.v38i4.2648

25. Senerath M.A.B.D. (1991). Biological studies on Coscinium fenestratum Colebr- (Menispermaceae). M. Phil thesis, University of Peradeniya, Peradeniya.

26. Staden J.V., Zazimalova E. \& George E.F. (2008). Plant growth regulators II: cytokinins, their analogues and antagonists. Plant Propagation by Tissue Culture, $3^{\text {rd }}$ edition (eds. E.F. George, M.A. Hall \& G.D. Klerk), pp. $205-226$. Springer Science + Business Media, Inc., The Netherlands.

27. Tushar K.V., George S., Remashree A.B. \& Balachandran I. (2008). Coscinium fenestratum (Gaertn.) Colebr. - a review on this rare, critically endangered and highly-traded medicinal species. Journal of Plant Sciences 3: $133-145$. DOI: https://doi.org/10.3923/jps.2008.133.145

28. Van N.D.N. \& Tap N. (2008). An Overview of the Use of Plants and Animals in Traditional Medicine Systems in Vietnam. TRAFFIC Southeast Asia, Greater Mekong Programme, Ha Noi, Vietnam.

29. Walter K.S. \& Gillett H.J. (eds.) (1998). 1997 IUCN Red List of Threatened Plants, p. 862. World Conservation Monitoring Centre, IUCN - The World Conservation Union, Gland, Switzerland and Cambridge, UK.

30. Warakagoda P.S. \& Subasinghe S. (2014). In vitro seed germination of Coscinium fenestratum (Gaertn.) Colebr. Annual Research and Review in Biology 4(23): 3549 - 3565. DOI: https://doi.org/10.9734/ARRB/2014/10558

31. Warakagoda P.S. \& Subasinghe S. (2015). Studies on seed germination of Coscinium fenestratum (Menispermaceae): a threatened medicinal plant. International Journal of Minor Fruits, Medicinal and Aromatic Plants 1(1): 37 - 46. 